\title{
Las 10 reglas de oro para un tatuaje responsable (normas básicas para un tatuaje responsable)
}

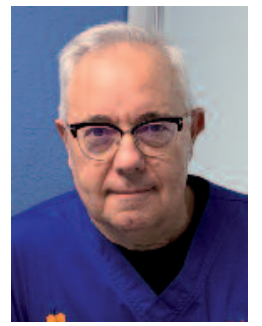

Donís Muñoz Borrás Consulta de Dermatología Médico-Estética del Dr. Donís Muñoz. Gandía (Valencia).

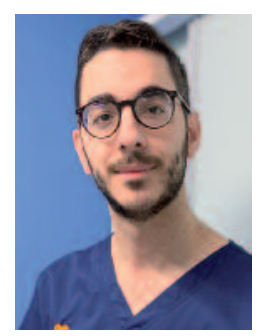

José María Ortiz Salvador Consulta de Dermatología Médico-Estética del Dr. Donís Muñoz. Gandía (Valencia).

\section{INTRODUCCIÓN}

En los últimos años, hemos asistido a una creciente expansión del tatuaje artístico, que ha pasado de ser una práctica marginal y minoritaria a un fenómeno de masas imparable, que necesita ser regulado y atendido. La información previa y veraz al aspirante a tatuarse acerca de los riesgos de esta técnica debería resultar obligada a la hora de asumir los potenciales riesgos voluntariamente y con conocimiento de causa. No obstante, la realidad es bien distinta, ya que un buen número de los pacientes tatuados, ante una reacción adversa, confiesan desconocer la existencia de estos y afirman que, de haberlo conocido, probablemente, no se habrían realizado su tatuaje. Las potenciales complicaciones, aun siendo excepcionales, existen y su existencia debería ser conocida previamente por los aspirantes.

Con el fin de procurar un tatuaje responsable, los usuarios que decidan realizárselo deberían conocer unas normas básicas que podríamos llamar las 10 reglas de oro para un tatuaje responsable y que detallamos a continuación.

\section{LAS 10 REGLAS DE ORO \\ PARA UN TATUAJE \\ RESPONSABLE}

\section{1. a Tomar la decisión serenamente}

En primer lugar, la decisión de tatuarse debería tomarse tras una información serena, no dejándose llevar por los impulsos del momento en un entorno de euforia o inconscientemente. Ello es especialmente útil en individuos con inestabilidad emocional o con trastornos de la personalidad. De igual modo, resulta poco razonable hacerlo bajo los efectos del alcohol u otras drogas.

\section{2. a Escoger el diseño deseado y su localización}

Una vez tomada la decisión de tatuarse, necesitamos saber qué es lo que nos queremos tatuar y dónde queremos situar el tatuaje. Respecto al diseño o motivo del tatuaje, cabe destacar que la interpretación personal y subjetiva que cada uno quiera darle a sus tatuajes está por encima de cualquier otra consideración. En absoluto se trata de una significación universal e inamovible, ya que un mismo elemento o dibujo, en función de su localización anatómica, de sus combinaciones temáticas, del color 
empleado o del entorno sociocultural en el que se realiza, simboliza una u otra cosa totalmente distinta ${ }^{1}$.

La localización corporal cambia por completo el sentido de un tatuaje. Un diseño situado en una zona privada deja de significar lo mismo cuando se tatúa en la cara o en otra zona claramente visible o imposible de cubrir, ya que ello le confiere automáticamente un carácter más desafiante y transgresor.

No menos importante resulta el conocer que, aún hoy en día, los tatuajes situados en zonas visibles pueden generar problemas de índole laboral. Así, en algunos países, determinados ministerios rechazan a los aspirantes con tatuajes visibles para formar parte de los cuerpos y fuerzas de seguridad del Estado. Asimismo, algunas empresas prohíben a sus empleados lucir tatuajes en zonas visibles.

\section{3. a Realizarlo en un estudio de tatuajes homologado}

Deben realizarse siempre en un estudio de tatuajes homologado por las autoridades sanitarias, evitando hacerlo en locales clandestinos, carentes de control sanitario. La importación ilegal de tintas o la realización de tatuajes en países carentes de normativa abre una nueva vía de contagio: las infecciones importadas. El entorno socioeconómico en el que se realiza un tatuaje resulta ser determinante en la posible transmisión de infecciones. Aunque estas son poco frecuentes en nuestro entorno, la globalización y la facilidad de tránsito de personas y mercancías entre distintos países están facilitando las infecciones importadas. Por ello, ante un efecto adverso, una detallada anamnesis debería recoger el lugar donde se realizó el tatuaje.

\section{4. ${ }^{\text {a }}$ Adecuada capacitación profesional del tatuador}

Para realizarse un tatuaje con garantías artísticas, no siempre es suficiente con realizárselo en un estudio de tatuajes debidamente homologado, ya que cada profesional posee una mayor o menor habilidad o especialización para realizar determinados estilos. Habrá que asegurarse de que el profesional que lo vaya a realizar esté artísticamente capacitado para hacérselo tal como lo desea. Sería aconsejable informarse y pedir referencias. Un buen número de personas tatuadas confiesan no estar satisfechas con el resultado artístico obtenido.

\section{5. a Exigir tintas homologadas}

La legislación española, como miembro de la Unión Europea (UE), aplica la resolución del Consejo de Europa ResAP (2008) sobre tatuajes y maquillajes permanentes. Esta, recomienda a los gobiernos de los Estados miembros que se elabore un listado exhaustivo de sustancias cuyo uso haya demostrado ser seguro en determinadas condiciones, con el fin de crear una lista "positiva». España, a través de la AEMPS (Agencia Española de Medicamentos y Productos Sanitarios), es uno de los países con una legislación sobre las tintas más restrictiva y exigente de la UE. Esto posibilita homologar un número muy limitado de tintas, que, según los tatuadores, son insuficientes, a la vez que manifiestan que estas proporcionan peores resultados artísticos que las tintas procedentes de otros países con legislaciones menos restrictivas. Como consecuencia de ello, se estima que el $80 \%$ de las tintas empleadas en Europa y también en España proceden de los Estados Unidos, en donde la FDA (Food and Drug Administration) no ejerce ningún tipo de control sobre ellas, alegando tener otras prioridades de salud pública. La compra de las tintas a través de internet impide un mayor control sobre el origen, estado de conservación o, incluso, sobre posibles falsificaciones.

Si añadimos a todo ello que los resultados artísticos obtenidos con las nuevas tintas sintéticas de color tipo azoicas son de mayor calidad y gozan de una gran aceptación por parte de los profesionales del tatuaje, ante un efecto adverso, el tatuador difícilmente va a reconocer el empleo de una 
tinta no homologada por el lógico miedo a las sanciones. Por todo ello, este alto grado de exigencia no ayuda a avanzar en la obtención de una lista positiva de tintas seguras; más bien, lo entorpece.

De cualquier modo, el usuario debería asumir responsablemente que, a pesar de que los efectos adversos de las tintas son excepcionales, no existen garantías absolutas respecto a su inocuidad, incluso de aquellas debidamente homologadas en España.

\section{6. a Tomar una foto del frasco de tinta}

Se debería tomar con el móvil una foto del frasco de la tinta o tintas con las que se le va a realizar el tatuaje y guardarlas durante un tiempo indefinido. En ella, debería figurar la marca del fabricante, el n. ${ }^{\circ}$ de registro sanitario, el índice de color (CI), el n. ${ }^{\circ}$ de lote, etc. Interés especial merece el conocimiento del CI, ya que podemos saber la composición del pigmento que contiene una tinta a través de este. El CI corresponde a una clasificación internacional de referencia para pigmentos y colorantes en general, utilizados en cualquier sistema de fabricación, no siendo exclusivo de las tintas para tatuar. También se emplea el número CAS (American Chemical Society).

La foto del frasco de tinta sería de gran ayuda, ya que nos permitiría conocer la composición del pigmento ante una futura reacción adversa frente a una tinta.

\section{7. a El color rojo, el más problemático}

En los últimos años, aunque el color negro sigue siendo el más empleado, este va siendo reforzado con una amplia gama de colores cada vez más llamativos y luminosos.

El aspirante a tatuarse debería saber que, entre todos ellos, el color rojo es el que puede llegar a crear más problemas de alergia o intolerancia, de forma imprevisible, tanto a corto como a largo plazo, incluso muchos años después. Hasta un $80 \%$ de las reacciones inflamatorias que asientan sobre las tintas de los tatuajes lo hacen sobre el color rojo (fig. 1). Antaño, el pigmento rojo

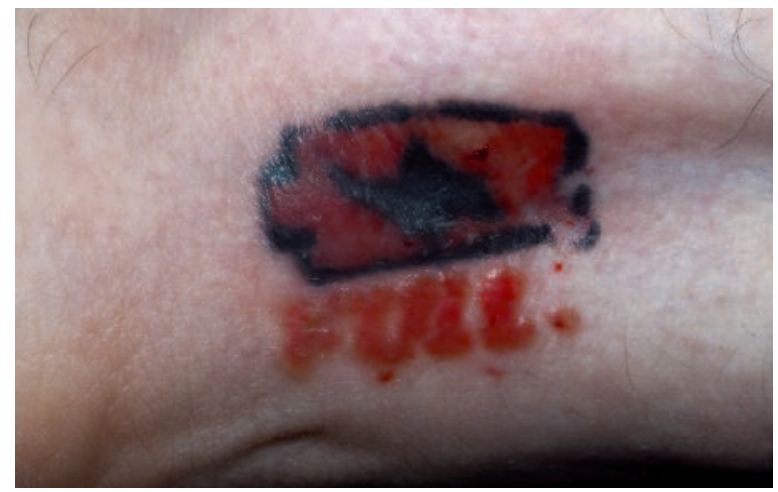

Figura 1. Reacción inflamatoria frente al pigmento rojo. Este es el responsable del $80 \%$ de las reacciones inflamatorias frente a la tinta de los tatuajes, incluso muchos años después de realizárselo.

destinado a los tatuajes se obtenía especialmente a partir de distintas sales metálicas como el selenito de cadmio (cadmio rojo) y el cinabrio (sulfuro rojo de mercurio), ambos metales pesados. Frente al peligro que representaban para la salud pública, estos fueron prohibidos en 1976 por la FFDCA (Federal Food, Drug and Cosmetic Act) y progresivamente sustituidos por pigmentos orgánicos sintéticos de tipo azoico, que son los que más se emplean en la actualidad, al proporcionar colores más duraderos, vistosos y apreciados por los tatuadores. A pesar de ello, aún hoy en día, existe una cierta tendencia a relacionar los efectos adversos que asientan sobre las tintas rojas con las sales de mercurio ${ }^{2}$.

Nada más lejos de la realidad, ya que hace más de 40 años que el mercurio fue prohibido para la fabricación de pigmentos de cualquier tipo. En todo caso, podrían encontrarse trazos de este formando parte de las impurezas en determinadas muestras analizadas. Hasta la fecha, no se han podido establecer los mecanismos etiopatogénicos implicados, aunque se especula con que podría deberse a la liberación de determinadas aminas aromáticas por los pigmentos azoicos.

\section{8. a El color negro, el más seguro}

Se estima que las tintas negras generan tan solo un $20 \%$ de las reacciones adversas. Los pigmen- 
tos empleados para obtener tintas negras desde tiempo inmemorial proceden mayoritariamente de la combustión del carbón, por lo que pueden generar importantes cantidades de hidrocarburos policíclicos aromáticos tanto en la piel como en los ganglios linfáticos ${ }^{3}$. A esto hay que añadir que se trata de nanopartículas, lo que facilita su difusión a través del sistema linfático, así como su penetración por la membrana celular, todo lo cual hace que —al menos, teóricamente- se trate de un pigmento cancerígeno, inmunotóxico y citotóxico ${ }^{4}$. No obstante, la realidad es que todos estos potenciales peligros no se traducen en evidencia clínica constatable, ya que, a pesar de que estos pigmentos vienen empleándose para realizar tatuajes desde hace miles de años, no hay ninguna evidencia científica que relacione el pigmento negro con el cáncer de cualquier índole u otras enfermedades importantes, más allá de las excepcionales reacciones inflamatorias.

\section{9. ${ }^{\text {a }}$ Si se padece de la piel, previamente se debe consultar con el dermatólogo}

En el supuesto de presentar determinadas enfermedades de la piel tales como la psoriasis, el vitíligo, la alergia al níquel, la dermatitis atópica, eccemas u otras enfermedades crónicas cutáneas, es mejor no realizarse tatuajes o, en todo caso, consultar con el dermatólogo. Existe una contraindicación relativa en los pacientes con enfermedades de la piel que se acompañan del fenómeno isomorfo de Köebner.

Los pacientes con antecedentes de alergia de contacto al níquel o a otras sustancias tienen más posibilidades de desarrollar alergia a las tintas de tatuar. En tal caso, se corre un mayor riesgo, aunque se puede considerar una contraindicación no absoluta, más bien, relativa.

\section{0. a La tinta negra, la más fácil de eliminar con láser}

El láser Q-switched de pulso corto, de nanosegundos, en diferentes longitudes de onda, es el más empleado en la eliminación de tatuajes. Más recientemente, se están empleando los láseres de picosegundos, con los que se obtienen mejores resultados.

A la hora de eliminar un tatuaje, los de color negro, azul oscuro y rojo puro (sin mezcla con otros pigmentos como el dióxido de titanio) son los más fáciles de borrar, mientras que el color amarillo, el verde y, especialmente, el azul turquesa entrañan mayor dificultad (fig. 2). El color blanco, por lo general, no se puede eliminar. En ocasiones, la mezcla de colores, inadvertida inicialmente, puede aumentar considerablemente el número de sesiones necesarias.
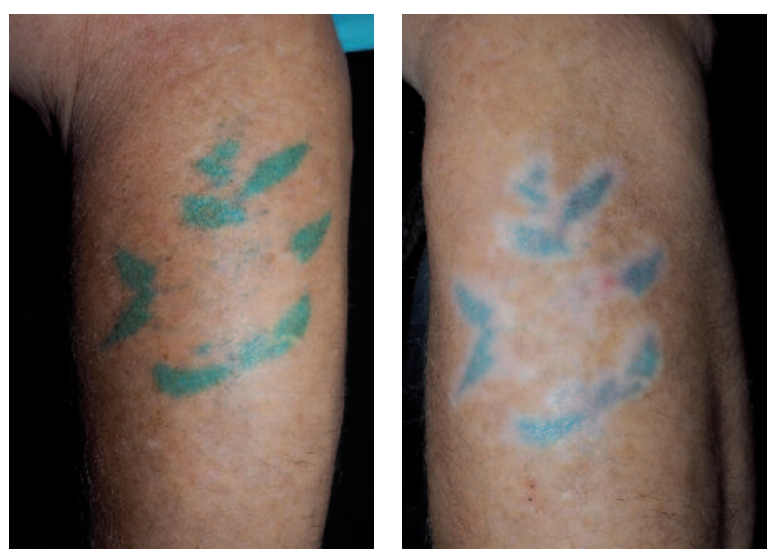

Figura 2. Escaso grado de aclaramiento de un tatuaje verde azulado tras nueve sesiones con láser en modo Q-switched de rubí, específico para este color, aun empleando fluencias altas.

También los tatuajes con mucho grosor o densidad de tinta requieren muchas más sesiones de láser y quedan peor.

\section{CONCLUSIÓN}

Todas estas «reglas de oro», dirigidas a los usuarios y extensibles a los medios de comunicación, podrían ser de utilidad en campañas divulgativas de salud pública (tabla 1).

Debería llegar un día en el que todo aspirante a tatuarse dispusiera de un consentimiento infor- 
Muñoz Borrás D et al. Las 10 reglas de oro para un tatuaje responsable (normas básicas para un tatuaje responsable)

Tabla 1. Las 10 reglas de oro para un tatuaje responsable

Instrucciones dirigidas a los aspirantes a tatuarse:

1. Tomar la decisión de tatuarse serenamente, informándose bien antes de realizárselo.

2. Tener claro qué es lo que nos queremos tatuar y en qué parte del cuerpo lo hacemos.

3. Realizarlo siempre en un estudio de tatuajes debidamente homologado.

4. Asegurarnos acerca de la adecuada capacitación artística del tatuador elegido.

5. En la realización del tatuaje, exigir siempre tintas homologadas en la Unión Europea.

6. Tomar una foto con los datos del frasco de tinta y guardarla durante un tiempo indefinido.

7. Debe saber que el color rojo es el más problemático, al generar más efectos adversos.

8. El color negro es el más seguro, si bien, no existen garantías absolutas sobre su inocuidad.

9. Si padece alguna enfermedad de la piel, mejor consulte con su dermatólogo previamente.

10. El negro es el más fácil de eliminar con láser, y el azul turquesa, el más difícil.

mado con toda esta información. En la actualidad, por desgracia, salvo honrosas excepciones, esto es algo impensable, al menos, en España.

\section{BIBLIOGRAFÍA}

1. Taringa! El significado de los tatuajes. 2008. Disponible en: https://www.taringa.net/+arte/el-significado-de-los-tatuajes huxvk

2. Yazdian-Tehrani $\mathrm{H}$, Shibu MM, Carver NC. Reaction in a red tattoo in the absence of mercury. Br J Plast Surg. 2001; 54(6):555-6.

3. Regensburger J, Lehner K, Maisch T, Vasold R, Santarelli F, Engel $\mathrm{E}$, et al. Tattoo inks contain polycyclic aromatic hydro- carbons that additionally generate deleterious singlet oxygen. Exp Dermatol. 2010;19(8):e275-81.

4. Høgsberg T, Loeschner K, Lof D, Serup J. Tattoo inks in general usage contain nanoparticles. Br J Dermatol. 2011;165(6): $1210-8$.

\section{BIBLIOGRAFÍA RECOMENDADA}

Muñoz D. Conceptos generales sobre los tatuajes. En: Muñoz D. Tratado sobre los tatuajes. Claves para su eliminación con láser. Buenos Aires: Journal; 2017. p. 1-38.

Muñoz D. Leyendas urbanas y otros temas relevantes acerca de los tatuajes. En: Muñoz D. Monografías de Dermatología. Tatuajes. Aula Médica Edic. 2019;32(2):120-37. 